\title{
Michael Suk, Beate P. Hanson, Daniel C. Norvell, David L. Helfet: Musculoskeletal outcomes measures and instruments 2 vols; Selection and assessment upper extremity. Lower extremity
}

\author{
Georg Thieme Verlag, Stuttgart, New York, 2009 Various pag. w. ills. and tabs. \\ $19 \mathrm{~cm}$, Softcover, $€$ 129.95, CHF 216.00, ISBN: 978-3-13-141062-7
}

Pierre Kehr

Received: 15 August 2009 / Accepted: 18 August 2009 / Published online: 30 August 2009

(C) Springer-Verlag 2009

In contrast to the other books on this topic, this book analyzes the scores of tests but does not describe them.

After a first part explaining the principle and the means of this analysis, each chapter gathers various tests by articulations (shoulder, elbow, wrist and hands).

Each test is analyzed in the same manner with the initial bibliographical reference, the contents of the test (symptoms, work, sport...) and its validation (list of the publications) against other tests. The methodological evaluation and the clinical utility are noted on 10, making it possible to classify the various tests according to their utility.
Certain tests are found in several chapters and tested according to their utility for each articulation. For example, the DASH: 9 for the shoulder, 7 for the elbow and 7 for the hand and the wrist.

One realizes that the tests often used and validated for comparison in literature are often most relevant.

This is a little difficult, but very useful book, which analyzes "comprehensive" tests and discovers some less known ones.

No funds were received in support of this study.

Alain Graftiaux
P. Kehr $(\bowtie)$

ArgoSpine, Strasbourg, France

e-mail:kehrpier@aol.com 